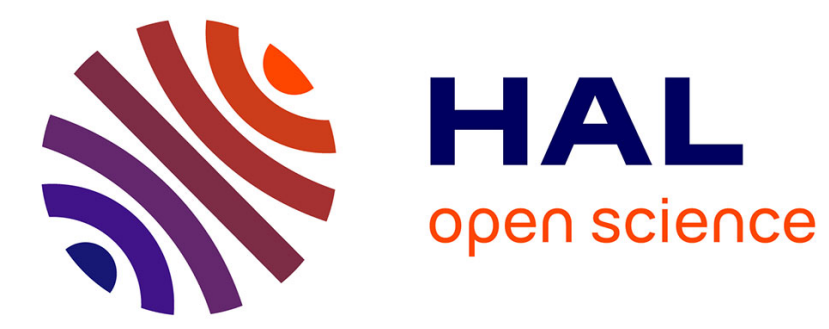

\title{
Stress generated by the freeze-thaw process in open cracks of rock walls: empirical model for tight limestone
}

\author{
Marion Bost, Ahmad Pouya
}

\section{To cite this version:}

Marion Bost, Ahmad Pouya. Stress generated by the freeze-thaw process in open cracks of rock walls: empirical model for tight limestone. Bulletin of Engineering Geology and the Environment, 2016, 17 p. 10.1007/s10064-016-0955-6 . hal-01526043v2

\section{HAL Id: hal-01526043 \\ https://hal.science/hal-01526043v2}

Submitted on 9 Jun 2017

HAL is a multi-disciplinary open access archive for the deposit and dissemination of scientific research documents, whether they are published or not. The documents may come from teaching and research institutions in France or abroad, or from public or private research centers.
L'archive ouverte pluridisciplinaire HAL, est destinée au dépôt et à la diffusion de documents scientifiques de niveau recherche, publiés ou non, émanant des établissements d'enseignement et de recherche français ou étrangers, des laboratoires publics ou privés. 


\section{Stress generated by the freeze-thaw process in open cracks of rock walls: empirical model for tight limestone} AQ1

Marion Bost, 1,*

Phone: 0033472142488

Email: marion.bost@ifsttar.fr

Ahmad Pouya, 2

Phone 33164153565

Email Ahmad.Pouya@enpc.fr

1 IFSTTAR, GERS, RRO, 25 Avenue François Mitterrand, Case 24, 69675 Bron Cedex, France

2 Laboratoire Navier (IFSTTAR,ENPC,CNRS), Université Paris-Est, Ecole des Ponts ParisTech, 6-8 Av. Blaise Pascal, Cité Descartes Champs sur Marne, 77455 Marne La Vallée Cedex 2, France

\section{Abstract}

In mountainous areas, freezing is a prominent phenomenon for weathering processes in rock walls. A freezing front penetrates rock crack networks and causes its propagation. To study the evolution of rock mass stability, a suitable model of stress generated by freezing in open rock cracks is needed. This stress evaluated by the simple volume expansion model in a closed crack is too high to be realistic. In this paper, we present an assessment method for this stress and some results. Different experiments on notched limestone specimens submitted to freeze-thaw cycles were performed. Three different tight limestones (Larrys, Chamesson, Pierre de Lens) were tested. Actually, the stress generated by freezing begins to grow at the top of the notch where an ice plug is created and makes it possible for higher stresses to develop in deeper parts of the notch. Consequently, the 
stress induced by freezing depends on the geometry of the open crack represented by the notch. This value is, however, limited by the permeability of the surrounding rock matrix. A model of the stress evolution generated by freezing along an open crack was established and its envelope curve, named maximum stress, was parameterized. This maximum stress generated by freezing along the crack is completely defined by knowledge of the pore network of the limestone matrix and the geometry of the crack.

AQ2

\section{Keywords}

Freezing alteration

Limestone

Crack

Stress model

\section{Introduction}

Predicting rockfalls has been a constant difficulty found in infrastructure design and maintenance and, more generally, risk management in mountainous areas (PIARC 1999; Groupe Falaise 2001). The assessment of the stability of rock slopes has been intensively investigated in recent decades, but the time-dependency of this risk, i.e. to know how the rockfall occurrence probability evolves with time, was less studied despite its importance for decision-making in the risk management process. Time-dependency characterization of rockfall risk requires the knowledge of weathering processes that affect the rock mass. Weathering here designates all the physico-chemical processes that occur in a rock mass and affect its mechanical strength. Weathering may be composed of different origins according to the physical nature of rock, geological structure of the rock mass, existence of rock joints and fractures, climatic zone, etc. (Javey 1972; Clark and Small 1982; Derruau 1996; Matsuoka 2008). In the case of rocky cliffs in mountainous areas, field observations suggest that freezing is a prominent phenomenon (Fahey and Lefebure 1988; Wegmann and Gudmundsson 1999; Frayssines and Hantz 2006; Amitrano et al. 2010, 2012; Mateos et al. 2012). In 1666, the destructive power of ice formation was revealed by Huygens (1666) who succeeded in bursting a gun barrel filled with liquid water by winter freezing. Indeed, the near absence of vegetation on a cliff depending on 
the slope of its face leaves rock exposed to temperature and humidity changes. During the cold season, a freezing front can be created and propagated in the rock mass. It penetrates more or less deeply in crack networks and causes their propagation (Valadas 1975; Letavernier 1984; Davies et al. 2001; Matsuoka 2001; Murton et al. 2006; Matsuoka and Murton 2008; Lévy et al. 2010; Krautblatter et al. 2013). To quantify the evolution of crack networks during the cold season, a model of stress generated by freezing in the cracks is needed. In this study, we present some experimental and theoretical contributions to such a model. As limestone is one of the most common rocks in France, three different limestones from three different areas in France (Yonne, Côte d'Or, Gard) were used in this study (Fig. 1).

\section{Fig. 1}

Location map for the three studied limestones (Larrys, Chamesson, Pierre de Lens)

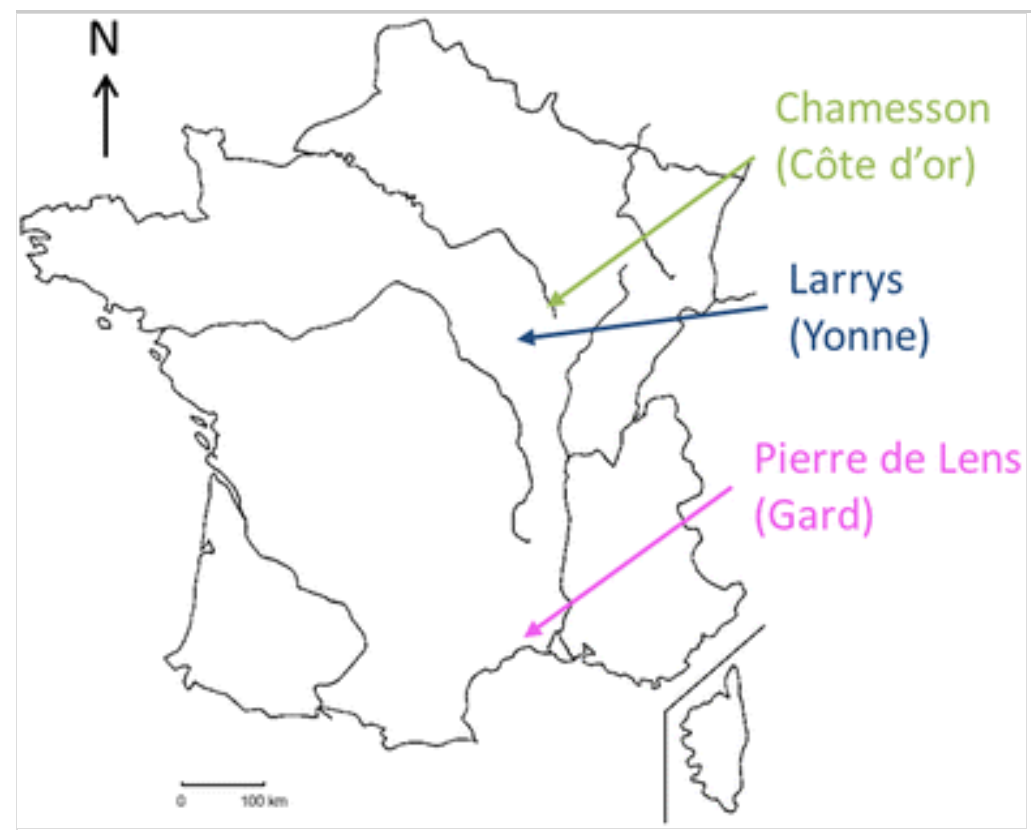

First, the inadequacy of some existing models for freezing-induced stress with sharp simplifications is highlighted. Then, the experimental results of an initial experiment on a cubic specimen to measure the stress generated by water freezing along an open crack in limestone are presented. On the basis of these data, a new experiment on a hollow cylindrical specimen with several stress measurements along an open crack is described and an empirical model of freezing stress in open rock cracks is proposed. Additional experiments were performed to parameterize the stress model. The influences of rock characteristics and geometry of the crack on the model parameters are discussed. Finally, the model is illustrated by application to a real unstable 
rock mass in the French subalpine ranges.

\section{Existing models of the stress generated by freezing in a crack}

\section{Models based on water volume expansion in a closed crack}

Unlike other materials, water expands as it changes from a liquid to a solid state. During the formation of ice crystals, molecules are arranged in a regular hexagonal lattice with hydrogen bonds (Berthier 1958; Teixeira 2001), with a distance between molecules that makes the network less compact than the liquid state. The specific volume of ice is well above that of liquid water (Lliboutry 1964) and the corresponding volume increase is about $9 \%$ at atmospheric pressure. This basic data was used in different ways to estimate the stress generated by freezing in materials.

\section{Model of water inclusion in an elastic body}

A simple estimation of the freezing stress is obtained by modeling a spherical inclusion (water-ice) in an infinite elastic matrix (rock) with the inclusion undergoing stress-free strain in the sense of Eshelby (1957) corresponding to the $9 \%$ volume expansion during the freezing process. The solution to this problem can be deduced from the classical solutions in linear elasticity for displacement and stress fields in a hollow sphere (Pouya 20011991; Salençon 2002). Lliboutry ( 1964 ) developed a model based on the same idea but replacing the infinite elastic matrix, in an approximate way, by some elastic interaction of the ice and the walls of the rock crack, and taking also into account the air initially dissolved in water and freed during the freezing process. The estimations obtained by these two models are given in Table 1 , with the parameters for ice and rock (limestone) defined in Table 2 . The free expansion is given by $1 /\left(\gamma_{g}-1\right)$ with $\gamma_{g}$ representing the relative density of ice. The expression for a spherical inclusion in an infinite elastic matrix leads to a 700-MPa stress value in the ice inclusion, when the Lliboutry (1964) estimation is about $750 \mathrm{MPa}$. It is not possible to discuss more the origin of the difference between the two estimations because the Lliboutry model (1964) concerning the elasticity of the crack wall is very approximate, and its model contains an additional contribution of the air phase. 


\section{Table 1}

Stress generated by water freezing in a spherical hole in an infinite rock matrix

\begin{tabular}{|c|c|c|}
\hline \multirow{2}{*}{ References } & \multirow{2}{*}{ Equation } & Stress value \\
\hline & & $M P a$ \\
\hline Lliboutry ( 1964 ) & $\sigma=\frac{1}{3} \frac{E_{r} E_{g}\left(\frac{1}{\gamma_{g}}-1\right)}{E_{g}\left(1-2 \nu_{r}\right)+\frac{1}{\gamma_{g}} E_{r}\left(1-2 \nu_{g}\right)}$ & 748 \\
\hline Pouya ( 1991 ) & $\sigma=\frac{1}{3} \frac{E_{r} E_{g}\left(\frac{1}{\gamma_{g}}-1\right)}{\frac{1}{2} E_{g}\left(1+\nu_{r}\right)+E_{r}\left(1-2 \nu_{g}\right)}$ & 700 \\
\hline
\end{tabular}

\section{Table 2}

Physical and mechanical parameters of ice and rock (limestone)

\begin{tabular}{|l|l|l|}
\hline Parameters & Ice (Lliboutry 1964) & Larrys limestone (Bost 2008) \\
\hline Young's modulus $E$ & 9000 & 64,900 \\
\hline $\mathrm{MPa}$ & & \\
\hline Poisson's ratio $v$ & 0.36 & 0.34 \\
\hline- & & \\
\hline Relative density $\gamma$ & 0.92 & 2.46 \\
\hline- & & \\
\hline
\end{tabular}

AQ3

AQ4

Limitations of the model of volume expansion in a closed crack

It is clear that both these estimates are unrealistic because $700 \mathrm{MPa}$ exceeds largely the strength of limestone and ice. Rock in this model undergoes tensile stress and the tensile strength of limestone is at most a few tens of MPa (Table 3 ). Moreover, according to the state diagram of ice prepared by Bridgman (1912), beyond 200-MPa compression, either ice melts or is compacted by a rearrangement of its molecules. If this rearrangement is taken into account, then a lower stress estimate will be obtained. However, the main flaw of these estimates, leading to very high stress values, resides in the 
assumption of a closed volume for water freezing and expansion, which is physically not true and must be revised.

\section{Table 3}

Shear strength values for different types of rock (Panet 1976)

\begin{tabular}{|l|l|}
\hline \multirow{2}{*}{ Rock } & Shear strength \\
\hline Limestone & MPa \\
\hline Granit & $1-15$ \\
\hline Basalt & $10-20$ \\
\hline
\end{tabular}

Matsuoka (2008) showed also by field observations and measurements that crack openings during cold seasons do not exactly follow the predictions based only on the water volume expansion. The crack opening would be certainly related to the amount of water initially present in the crack but also to the intensity of the cold period (its duration and the minimum negative temperature attained during the cold season). These effects are not taken into account in the simplified models presented above. Moreover, the assumption of freezing expansion in a closed volume does not consider the diffusion or extrusion process of water or ice into the surrounding porous rock that takes place during freezing in cracks as shown by different observations. An extrusion of ice during freezing in the porous matrix was observed by Berthier (1958) by a simple experiment: a water-saturated brick was left to soak immersed in an unfreezing liquid which was immiscible with water. The brick became covered with ice when the temperature dropped to negative values. Ice is also a viscous material (Akyurt et al. 2002) subject to creep when the temperature is not too low. Djaballah Masmoudi (1998) demonstrated the migration of water in solid and liquid states between the crack and the rock matrix under negative temperatures. All these phenomena justify the incompatibility with the stress generated by the model assuming only freezing expansion in a closed volume.

Finally, the role of the crack's surrounding rock which is also subject to propagation of the freezing front might not be overlooked. The behavior of water-saturated porous rock in cold environments is still unpredictable. The total bulk strain results from the expansion of water under freezing and contraction of the rock skeleton with a temperature decrease. It could be 
thought, at first, that more porous rocks saturated with water will expand as a result of ice formation. However, the contraction of some limestone was observed during freezing-thawing cycles (Prick 1995). In fact, the heterogeneity of the pore size distribution leads to a heterogeneous freezing process in the rock. As a consequence, in addition to the stress due to volumetric expansion, a pressure gradient in the unfrozen water in the rock appears as well that makes its circulation possible within the pore space (Powers 1949; Powers and Helmuth 1953; Litvan 1978) as well as capillary stress at the water-ice interface (Everett 1961).

All these phenomena affect the stress induced by freezing in an open rock crack and make the simple volume expansion model too harsh and inadequate to represent the reality.

\section{Different attempts to establish new models for stress generated by freezing in a crack}

The multiplicity of phenomena involved in the phase transition process (fluid transfer, heat transfer, specific volume change and mechanical behavior) makes it difficult to establish a model integrating all these phenomena (Draebing et al. 2014). However, some authors attempted to establish more or less complete models based on theoretical considerations and some observations.

After having demonstrated the effect of freezing on the detachment of rock blocks in instable rock slopes, Ishikawa et al. (2004) determined a correlation model between the freezing-induced stress in the cracks and their opening measured in situ prior to failure. However, this model only considers the thermal stress developed in a crack. To assess the time-dependent opening of cracks during the freezing process, Djaballah Masmoudi (1998) applied the Stefan problem to study the stress resulting from the coupled mass and heat transfer at the interface between cracks and rocky faces. Although the agreement between experiment and theory obtained this way was quite correct, the model stems from the study of non-consolidated materials in a steady state and is also based on the hypothesis of continuous migration of water from rock to crack. It is not, therefore, suitable for low-porosity rocks and, so, freezing-induced stress for this type of rock cannot be determined. Hall ( 1986 ) determined, by back-analysis in the framework of fracture mechanics, the freezing stress in cracks that was required for crack propagation under failure mode I. The rock toughness for this analysis was 
determined beforehand by appropriate point load tests. However, this back-analysis is based on the assumption of uniform pressure, which is not true as will be seen further in this paper, and cannot give a correct estimate of the order of magnitude of real stress and, therefore, does not help to understand the involved mechanisms. Tharp (1987) also chose to model the stress exerted along the crack wall as being uniform and equal to the maximum value given by the Clausius-Clapeyron formula in thermodynamics. This formula expresses the pressure variation function of temperature during the phase change of a pure substance. In the case of the water freezing process in a porous rock, the basic assumptions of this formula become highly restrictive and inadequate since they assume the existence of a permanent unfrozen water reservoir and sufficient permeability of the rock to allow the unfrozen water to migrate towards the freezing front. Walder and Halet (1985) adapted to the problem of freezing stress estimate in cracks a model established for freezing stress in soils based on the principle of ice segregation. For horizontal cracks, their model reproduces the creation of ice lenses as observed in soils. However, their theory relies on the existence of a substantial water migration process that feeds the crack, an uniform pressure in the crack, and is not appropriate for cracks developed in low-porosity rock masses from the surface. Some contributions (Scherer 1999; Chen et al. 2000; Freire-Lista et al. 2015; De Kock et al. 2015) described mechanisms to explain ice crystallization-induced stress for the propagation of microcracks due to freeze-thaw inside porous materials like rock. The boundary conditions are also quite different from the conditions for open cracks in a rock wall.

All these theoretical models are concerned with one or two basic aspects under very restrictive assumptions or conditions that are far from the real conditions of the freezing weathering of fractured rock masses in cold areas. Besides, all of them ignored the important phenomena of ice extrusion in the porous matrix, and also the inhomogeneity of the temperature field during propagation of the freezing front in cracks; the temperature field has important effects on the stress developed in the crack. Eventually, none of them can be validated by stress measured in real cracks.

In this study, as mentioned in the Introduction, we do not intend to propose a new physical model; however, we suggest that every physical model has to be based on observation, experiments and measurements. We focus on a campaign of experiments carried out to measure the freezing stresses developed in open cracks in some varieties of limestone. The results obtained 
for different samples with different physical characteristics or geometries will be synthesized in some empirical formulae that can be used in future theoretical or practical investigations.

\section{Experimental study of the stress generated by freezing in an open rock crack}

\section{Principle}

The experimental approach chosen in this work to study the crack propagation in rock masses under freezing process consisted of replicating this phenomenon in a laboratory on an artificially cracked limestone sample (Fig. 2). A 15-cm side cube of limestone was prepared (Fig. 2b). By means of a saw, a 7-cm-deep and 2-mm-thick notch was formed in the middle of a face with a depth equal to a fraction of its height. No special care was given to the shape of the bottom of the notch. The size of the notch was also determined by the size of the saw, and the size of the specimen by the size of the cell for water saturation. The free lateral ends of the notch were sealed by an O-ring joint and a flexible product to take back the lateral stresses. A recess was further machined so as to be able to place pressure sensors in the notches with their sensitive surface in the extension of one of the faces (Fig. $3 \mathrm{~b}$ ). The sample was equipped with instruments before being saturated with water. The notch was then filled with water and the cube was subjected to freeze-thaw cycles until failure. During the cycles, the opening of the notch as well as temperature and pressure in different points of the notch were monitored (Fig. 3 a).

Fig. 2

Experimental approach to reproduce crack propagation in a rock mass due to freezing in a laboratory: a real case, $\mathbf{b}$ experimental specimen

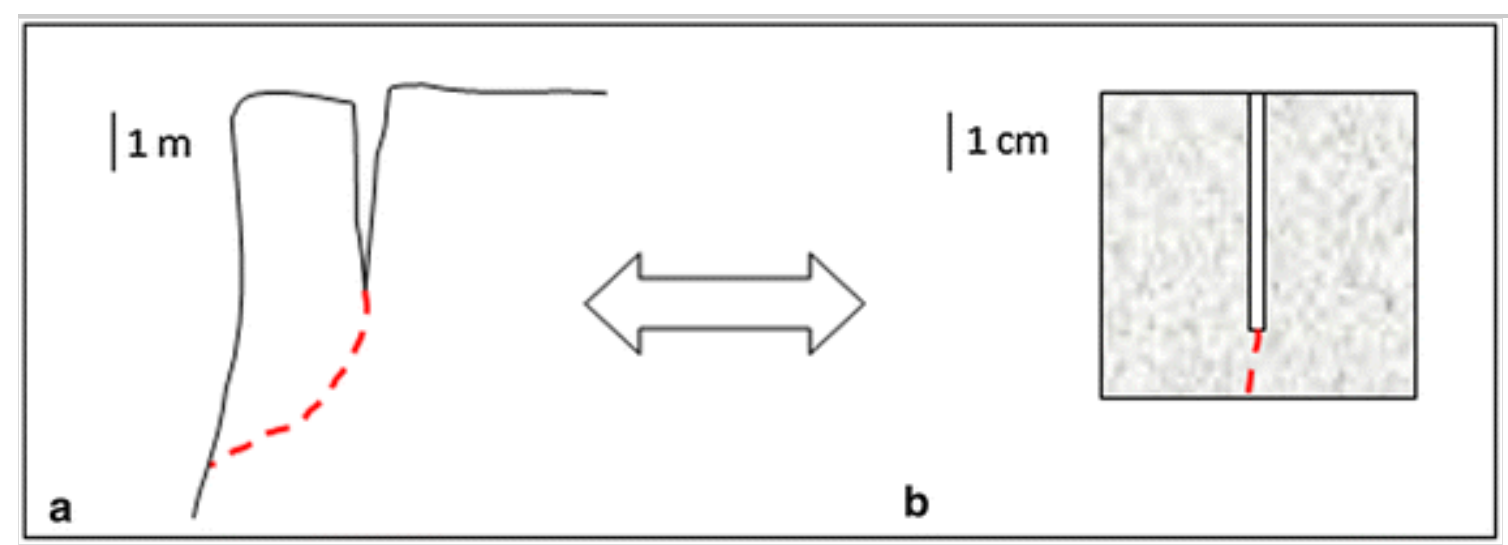

Fig. 3 
Larrys limestone cube specimen: a the instrumented notched cube, b two stress sensors to measure pressure inside the notch

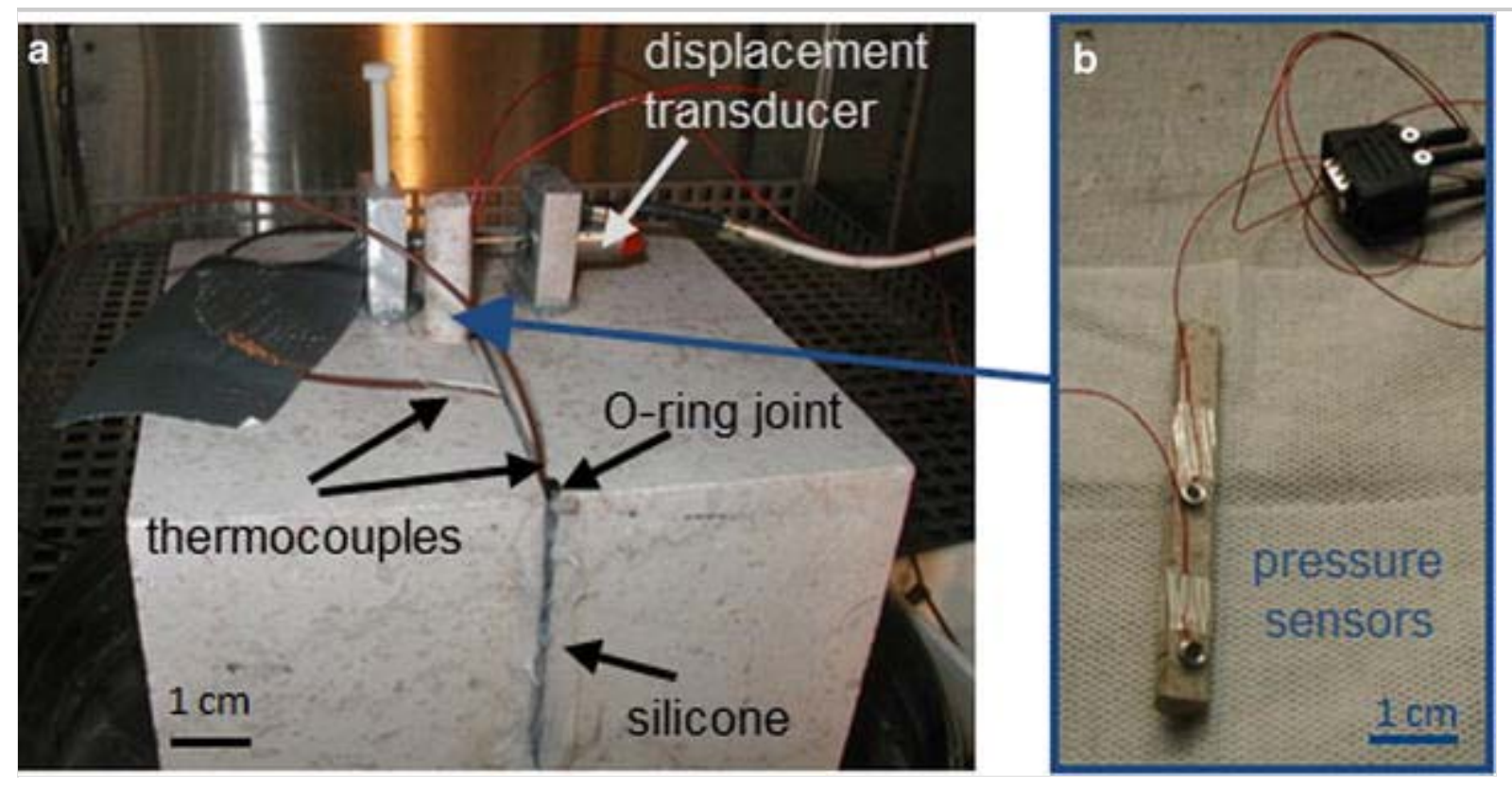

AQ5

In the following sections, we will call "notch" an artificially shaped discontinuity and "crack" a naturally formed discontinuity in rock.

\section{Experimental setting}

Choice of a reference limestone

As emphasized above, the stress developed by freezing in open cracks depends on a variety of parameters that cannot all be examined in this preliminary work. It was decided for this study to work with limestone only, which is constituted of a unique mineral, calcite, in order to set aside the effects of rock mineralogy. The Larrys limestone from the quarry of Moulin d'Arlot (Yonne, France) was chosen as a reference for all the experiments carried out in this study (Fig. 4). It is a pure Bathonien oolitic limestone with sparry cement and a low porosity value (Table $4: 4.3 \%$ ). This limestone is isotropic.

Fig. 4

Larrys limestone from the quarry of Moulin d'Arlot (Yonne, France) 


\section{ooid}

\section{$1 \mathrm{~cm}$}

\section{Table 4}

Characteristics of pore networks for three different limestones (Chamesson, Larrys, Pierre de Lens)

\begin{tabular}{|l|l|l|l|}
\hline \multirow{2}{*}{ Limestone } & $\begin{array}{l}\text { True } \\
\text { porosity }\end{array}$ & $\begin{array}{l}\text { Breakthrough } \\
\text { radius }\end{array}$ & Permeability \\
\hline $\begin{array}{l}\text { \% } \\
\text { Chamesson (Côtes-d'Or, }\end{array}$ & 17.5 & Nm & $\mathbf{1 0}^{-\mathbf{1 5}} \mathbf{m}^{\mathbf{2}}$ \\
\hline \begin{tabular}{l} 
France) \\
\hline Larrys (Yonne, France)
\end{tabular} & 4.3 & 75 & 0.88 \\
\hline $\begin{array}{l}\text { Pierre de Lens (Gard, } \\
\text { France) }\end{array}$ & 14 & 600 & 0.015 \\
\hline
\end{tabular}

\section{Freeze- thaw cycles}

To reproduce in a laboratory as accurately as possible what happens in nature, especially in terms of temperature variation, the freezing temperature for each freeze-thaw cycle was fixed at $-5^{\circ} \mathrm{C}$ and the thawing temperature at $20^{\circ} \mathrm{C}$. Each freezing or thawing stage was given a sufficient duration (7-10 h for freezing and $2-5 \mathrm{~h}$ for thawing) allowing the temperature at the bottom of the notch to reach thermal equilibrium. The sample was placed immediately under each temperature in order to perform one complete cycle per day.

As the ventilation of the temperature-controlled cell caused an unrealistic desaturation of the sample during the experiment, all the samples were first saturated with water under vacuum and then placed in a little water volume throughout successive cycles. Through this procedure it was possible to maintain the Larrys limestone's naturally high water content (S48, Hirschwald 
coefficient $\sim 90 \%$ according to AFNOR 1973; Hirschwald 1912; Bousquié 1979; Pellerin 1980; Iskandar 1990).

\section{Results}

Only two cycles were required for a visible crack to propagate from the initial notch of the specimen. The two pressure sensors placed at 20 and $60 \mathrm{~mm}$ deep in the notch showed that the stress evolution (Fig. 5) along the notch was globally the same in the first two freeze-thaw cycles, before failure occurred. At each depth in the notch, the stress increased up to a maximum value during the freezing period and then remained constant (at the base of the notch, Fig. 5: $60 \mathrm{~mm}$-cycle 1) or decreased (at the top of the notch, Fig. 5: $20 \mathrm{~mm}$ - cycle 1 and cycle 2). The maximum stress value reached in the freezing phase increased with the depth in the notch: the measured values were, respectively, 1 and $6 \mathrm{MPa}$ for the 20 - and $60-\mathrm{mm}$ depths. The maximum value migrated to depth during each cycle. The fact that during the second cycle the stress at the bottom of the notch decreased rapidly after the stress peak, unlike the first cycle, indicated a failure occurring at the end of the second cycle. This failure was confirmed by a visible crack that extended the notch and also by water losses observed in the notch at the beginning of the third cycle.

\section{Fig. 5}

Stress evolution at two depths of the notch $(20$ and $60 \mathrm{~mm})$ during the first two freeze-thaw cycles

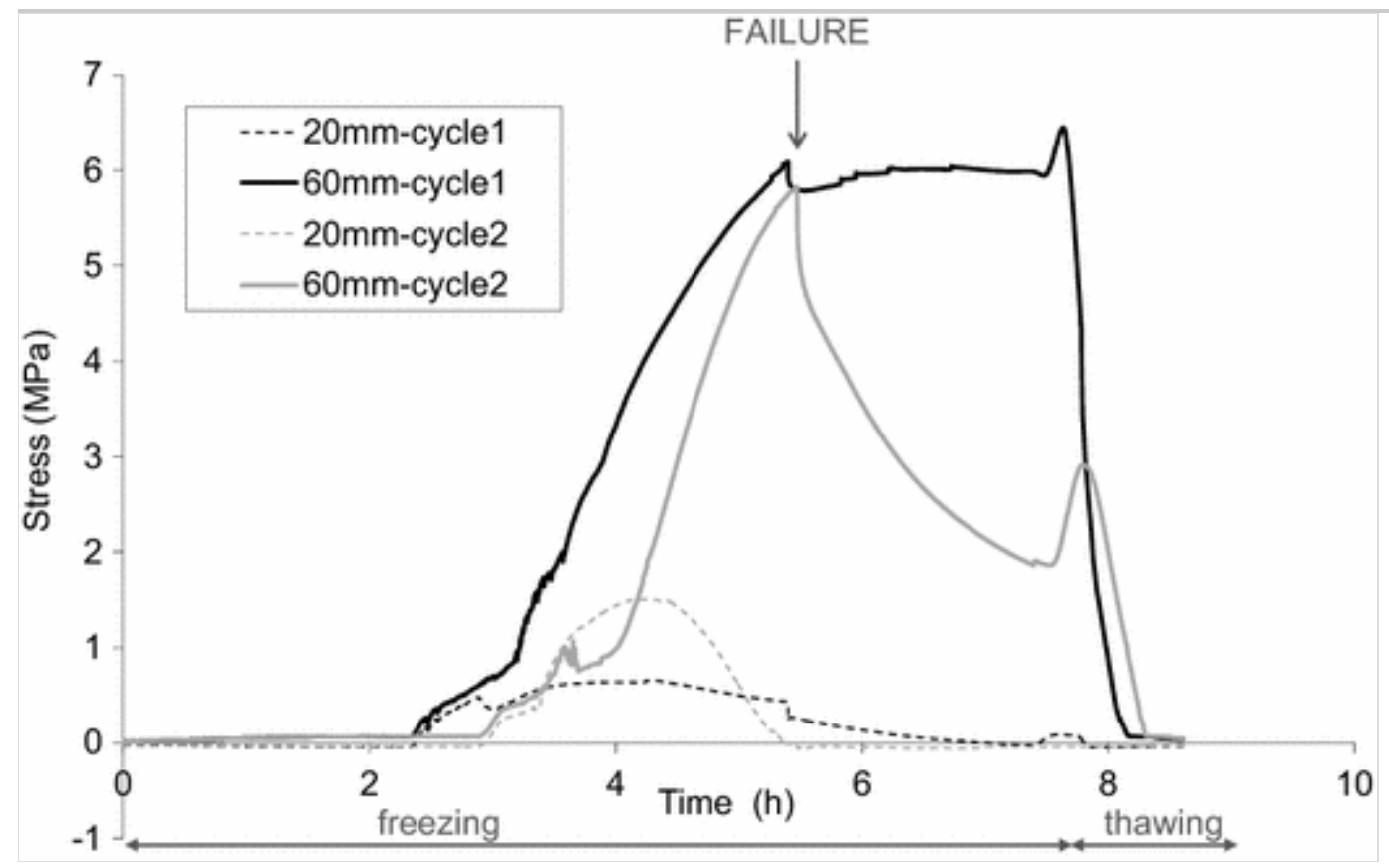


This experiment showed the stress inhomogeneity along a notch during a freeze-thaw cycle. However, stress was measured only at a limited number of depths because of practical difficulties in placing pressure sensors along the notch. To have a more complete view of the stress evolution during the freezing phase, a new experimental setting was conceived and is presented in the following section.

\section{Empirical model of the stress generated by freezing in an open rock crack}

\section{Principle of the new experimentation}

Instead of a cubic-shaped specimen, a hollow cylinder specimen in Larrys limestone was considered for a new series of tests. The specimen was saturated and filled with water and submitted to freeze-thaw cycles. Strain gauges were placed on the inner surface of the hollow cylinder allowing the axial and tangential strains to be monitored during the whole test duration up to failure. The tangential strain profile on the inner face along the specimen axis could, thus, be established. A back-analysis of this strain profile by the finite element code CESAR-LCPC (Bourgeois et al. 2012) determined the stress profile in the sample during the experiment.

\section{Experimental setting}

A hollow cylinder (height $=242 \mathrm{~mm}$, diameter $=100 \mathrm{~mm}$, wall thickness $=35 \mathrm{~mm})$ in Larrys limestone was over-cored on a part $(200 \mathrm{~mm})$ of its height (Fig. 6a). The 1-mm thick annular space obtained by this over-coring constituted the notch in which the freezing-induced stress was studied. The inner face of the cylinder was instrumented with five strain gauges fixed in biaxial quarter-bridges at different depths (Fig. 6b) and protected from water. They enabled monitoring over time the tangential and longitudinal strain profiles at the inner face of the tube. The sample was previously saturated with water at atmospheric pressure as the sample instrumented with strain gauges did not make possible a water saturation under vacuum to be performed just before the freeze-thaw cycle. Then, the notch was filled with water and the specimen placed in a climatic chamber and subjected to successive freeze-thaw cycles. The freezing and thawing temperatures were fixed as in the previous case and applied without a gradual cooling rate too. Temperatures were held constant until the specimen reached thermal equilibrium at the bottom of the notch. According to the temperature 
monitoring, 8-10 h were necessary for the temperature at the bottom of the notch to reach thermal equilibrium with surrounding air when freezing at $-5{ }^{\circ} \mathrm{C}$. Moreover, as in the previous case, it was noted that a portion of the water diffused into the notch and/or evaporated during each cycle and this required filling the notch with additional water before each new cycle.

\section{Fig. 6}

The instrumented, over-cored, hollow cylinder limestone specimen: a top view of the cylinder, $\mathbf{b}$ diagram of a longitudinal section of the cylinder
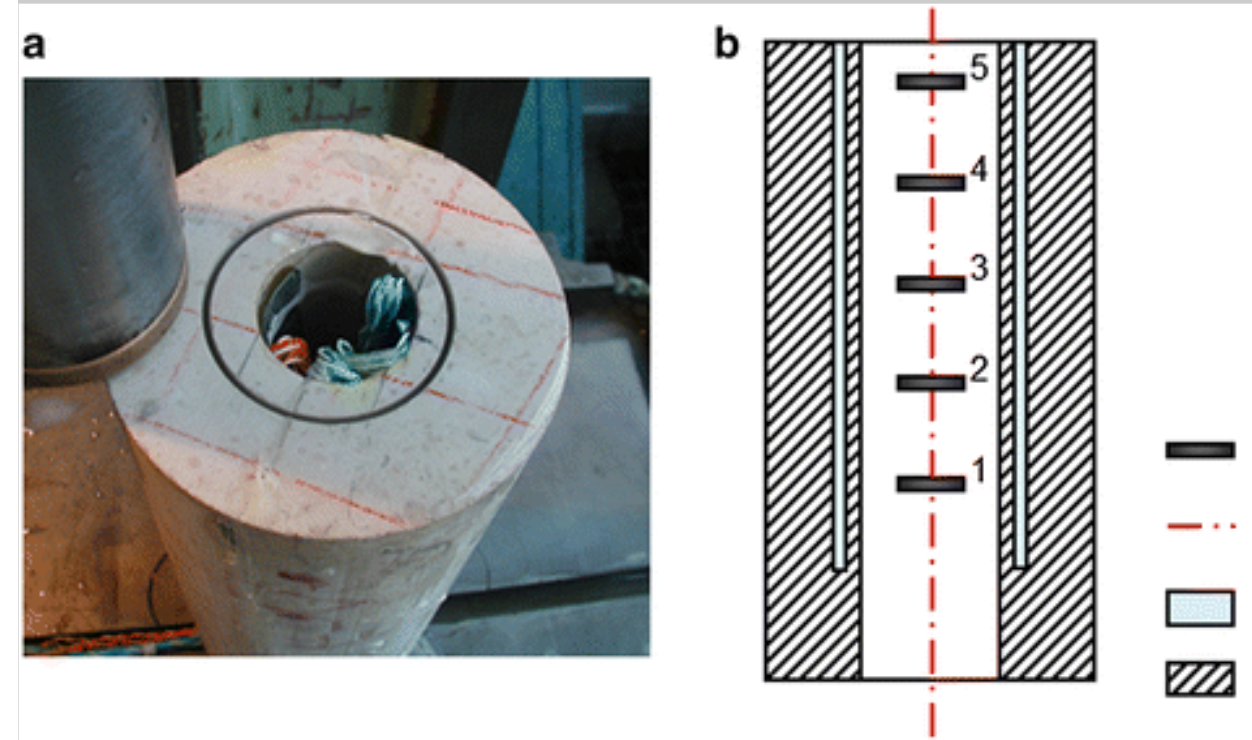

strain gauge

the axisymmetric axis of the tube water in the notch limestone tube

A back-analysis of the tangential strain $\varepsilon_{\theta}$ measured on the inner face of the tube (Fig. 7) at different heights (Fig. 6a) was carried out to determine the pressure $P$ exerted in the notch (Fig. 7).

\section{Fig. 7}

Diagram of a transversal section of the over-cored cylinder: $\varepsilon_{\theta}$, tangential strain measured on the inner face of the cylinder (radius $R_{i}$ ) and $P$, pressure applied in the notch on the outer face of the tube (radius $R_{e}$ ) 


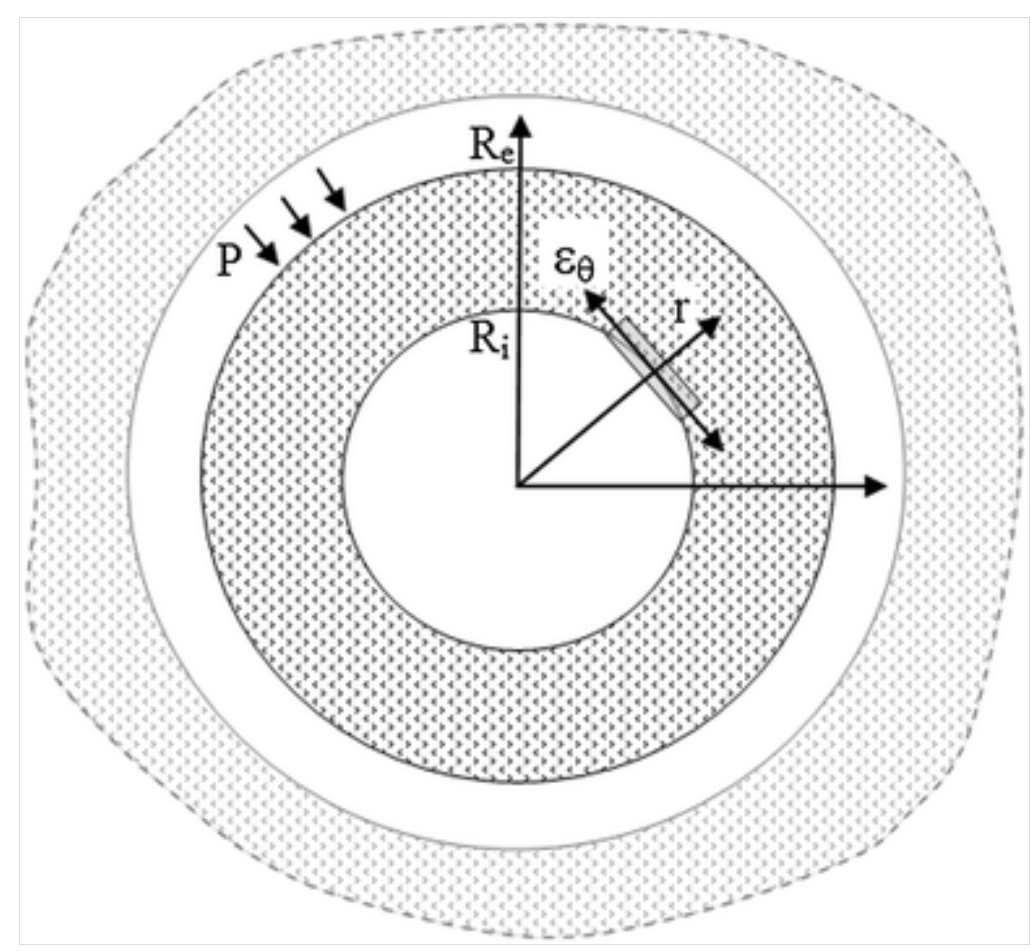

Note that the deformation $\varepsilon_{\theta}$ resulted from the application of the pressure $P$, but also from a thermal expansion or contraction of the rock due to temperature changes during freeze-thaw cycles. In order to filter thermal effects and also to thermally balance the strain gauges, an initial freeze-thaw cycle was performed without water in the notch. Therefore, the thermal expansion coefficient of each one of the gauges was determined.

Subsequently, the temperature was monitored at three points along the inner tube during the cycles and this enabled removal of the temperature effects in the measurements.

\section{Results}

During the freezing period, the phase change of water from liquid to a solid state deformed the inner cylinder by compression as indicated by the temperature-corrected values of the deformation measured by the different circumferential gauges (Fig. 8). Only two cycles were required again to reach failure for the specimen. Gauge 1 was the only one to suggest a new compression after the initiation of failure, and this was an indication that the failure was initiated in the specimen between gauges 1 and 2 (Fig. 8). From the data obtained on the five points all along the notch, a profile of the strain $\varepsilon_{\theta}$ could be established for the test duration interval. 
Fig. 8

Temperature-corrected strains measured during the second freeze-thaw cycle. Strain gauges are numbered from the bottom to the top of the tube (see Fig. 6b)

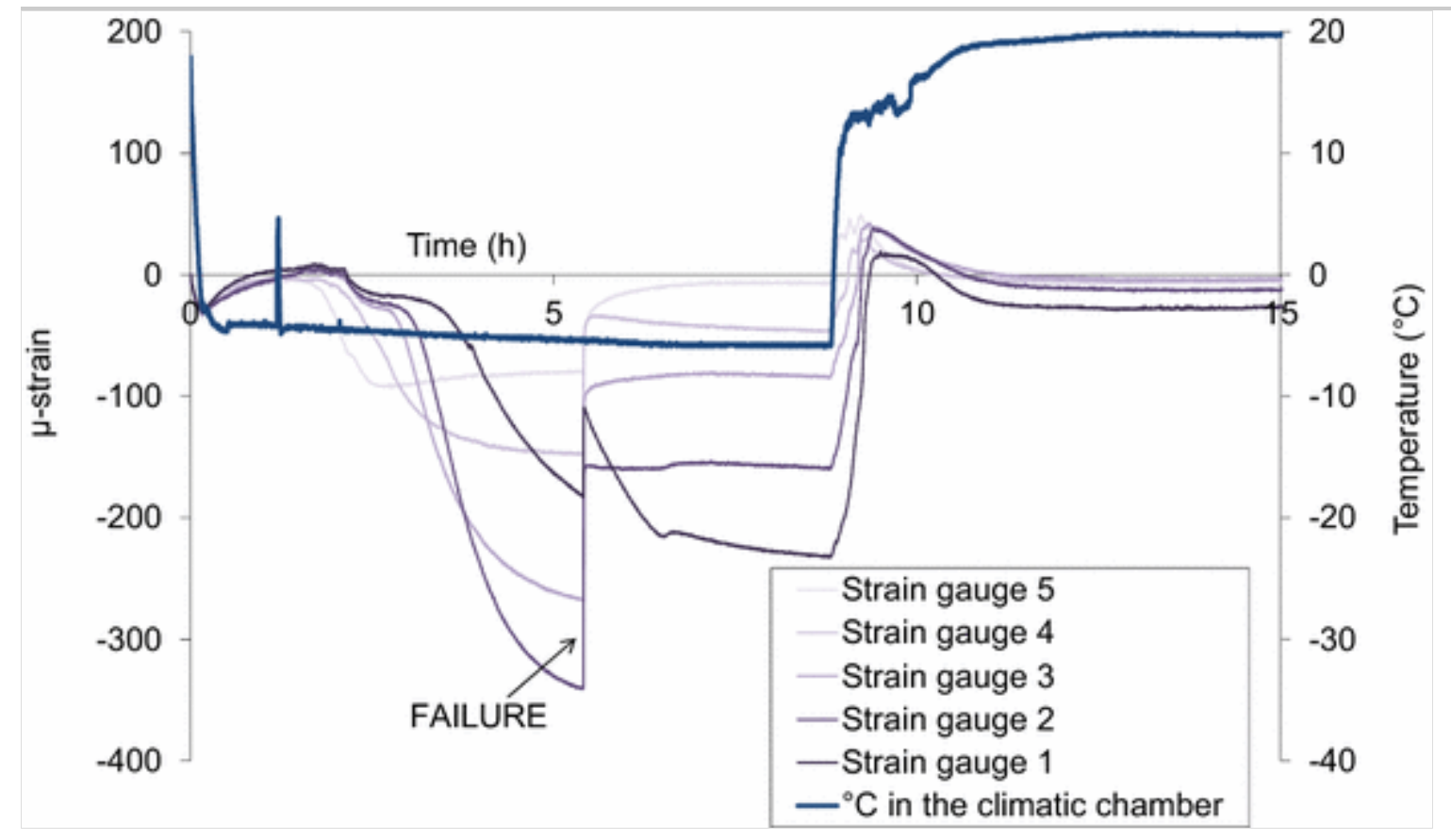

\section{Back-analysis}

A numerical modeling using the CESAR-LCPC finite element code was undertaken to determine, by back-analysis, the stress profile along the notch from the strain measured during the freeze-thaw cycles. The limestone behavior was assumed elastic for this analysis and its parameters (Table 1) were measured in this study by standard tests on limestone samples.

\section{Principle}

The cylindrical geometry of the specimen and the boundary conditions modeled the freeze-thaw experiment in an axial symmetry configuration around the specimen axis. The axis was designated by the $x$-axis in the sequel and parameterized by $x$ that represents the depth in the notch.

The tangential strain in the inner wall of the cylinder was measured at five points along the $x$-axis on this wall. A piecewise linear approximation of this $\varepsilon_{\theta}$ function was assumed and introduced in the numerical model for back-analysis. The radial stress on the same wall, as well as in the notch, was also approximated, in an initial approach, by a piecewise linear function of $x$ : 


$$
p(x)=\sum_{i=1}^{5} p_{i} \Psi_{i}(x)
$$

where:

- $p_{i}$ denotes the unknown pressure at the point $x_{i}$;

- $\psi_{i}$ is the basic 'shape function': it is a piecewise linear function equal to 1 at the measurement point $x_{i}$ and null at the other measurement points $x_{j}$ with $j \neq i$ (Fig. 9).

Fig. 9

The basic «shape» function $\Psi_{i}$ along the notch

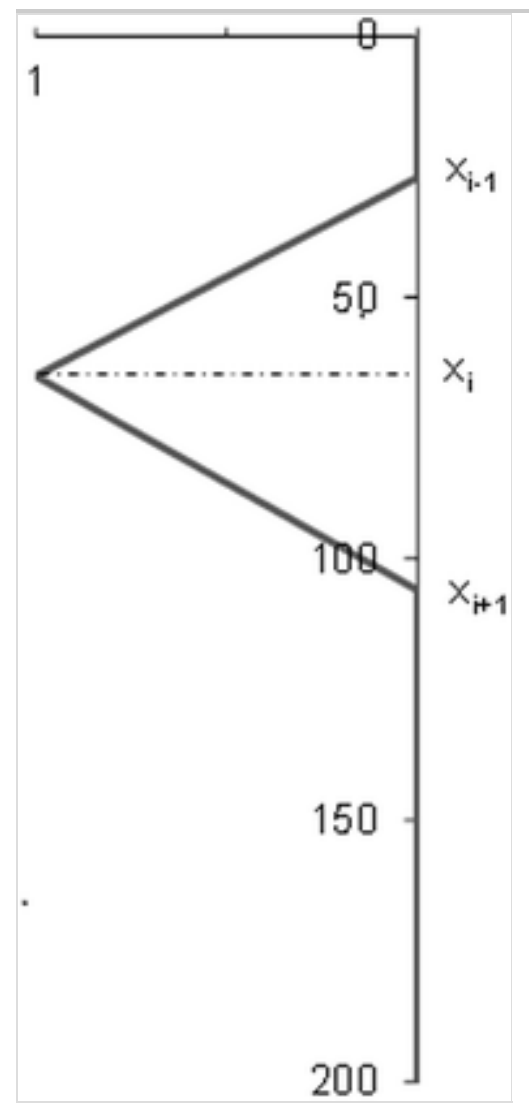

The set of five unknown parameters $\left\{p_{i}\right\}$ is to be determined by the analysis. Based on previous observations $(\S 3.3)$, the stress can be taken as being null at the top of the notch $(x=0)$ and constant between the last measurement point $\left(x_{5}\right)$ and the bottom of the notch. The basic shape functions $\psi_{i}$ reproduce these features.

For the linear elastic behavior of the tube, the total strain under the pressure 
load (Eq. 1) can be deduced from the superposition of strains induced by the basic load functions $\psi_{i}$. If the tangential strain along the $x$-axis induced by a pressure $p(x)=\psi_{i}(x)$ in the notch is designated by $\varepsilon_{i}(x)$, then:

$$
\varepsilon^{T}(x)=\sum_{i=1}^{5} p_{i} \varepsilon_{i}(x)
$$

where $\varepsilon^{T}(x)$ represents the tangential strain due to the pressure $p(\mathrm{x})$. The functions $\varepsilon_{i}(x)$ were computed numerically by the CESAR-LCPC code. The parameters $\left\{p_{i}\right\}$ were determined by comparing $\left\{\varepsilon_{j}^{M}\right\}$ and $\left\{\varepsilon_{j}^{T}\right\}$ which are, respectively, the measured values of tangential strain at points $x_{j}$ and the theoretical values at points $x_{j}$ according to Eq. (2). A least squares method was used based on the distance:

$$
D=\frac{1}{2} \sum_{j=1}^{5}\left(\varepsilon_{j}^{M}-\varepsilon_{j}^{T}\right)^{2}=\frac{1}{2} \sum_{j=1}^{5}\left(\varepsilon_{j}^{M}-\sum_{i=1}^{5} p_{i} \varepsilon^{i}\left(x_{j}\right)\right)^{2}
$$

where the values $\varepsilon^{i}\left(x_{j}\right)$ were deduced from numerical results. The minimization $\partial D / \partial p_{i}=0$ for $i=1, \ldots, 5$ leads to the following system of linear equations:

$$
A_{i k} p_{k}=B_{i}
$$

with:

$$
A_{i k}=\sum_{j=1}^{5} \varepsilon^{i}\left(x_{j}\right) \varepsilon^{k}\left(x_{j}\right), B_{i}=\sum_{j=1}^{5} \varepsilon^{i}\left(x_{j}\right) \varepsilon_{j}^{M}
$$

The resolution of this equation determined $\left\{p_{i}\right\}$ and also the whole pressure function $p(x)$.

Shape of the stress along the notch as the piecewise linear model The assumption of linear elastic behavior limited the analysis to the first freeze-thaw cycle only, the single one before failure. However, the continuous monitoring of the gauges during cycles allowed a piecewise linear shape to be defined as an approximation for the stress profile along the notch at every moment. Thus, the stress profile along the notch was determined every hour during the freezing part of the first cycle (Fig. 10). 


\section{Fig. 10}

Stress profiles along the notch at different times (each hour from 1 to $9 \mathrm{~h}$ ) during the first freeze-thaw cycle

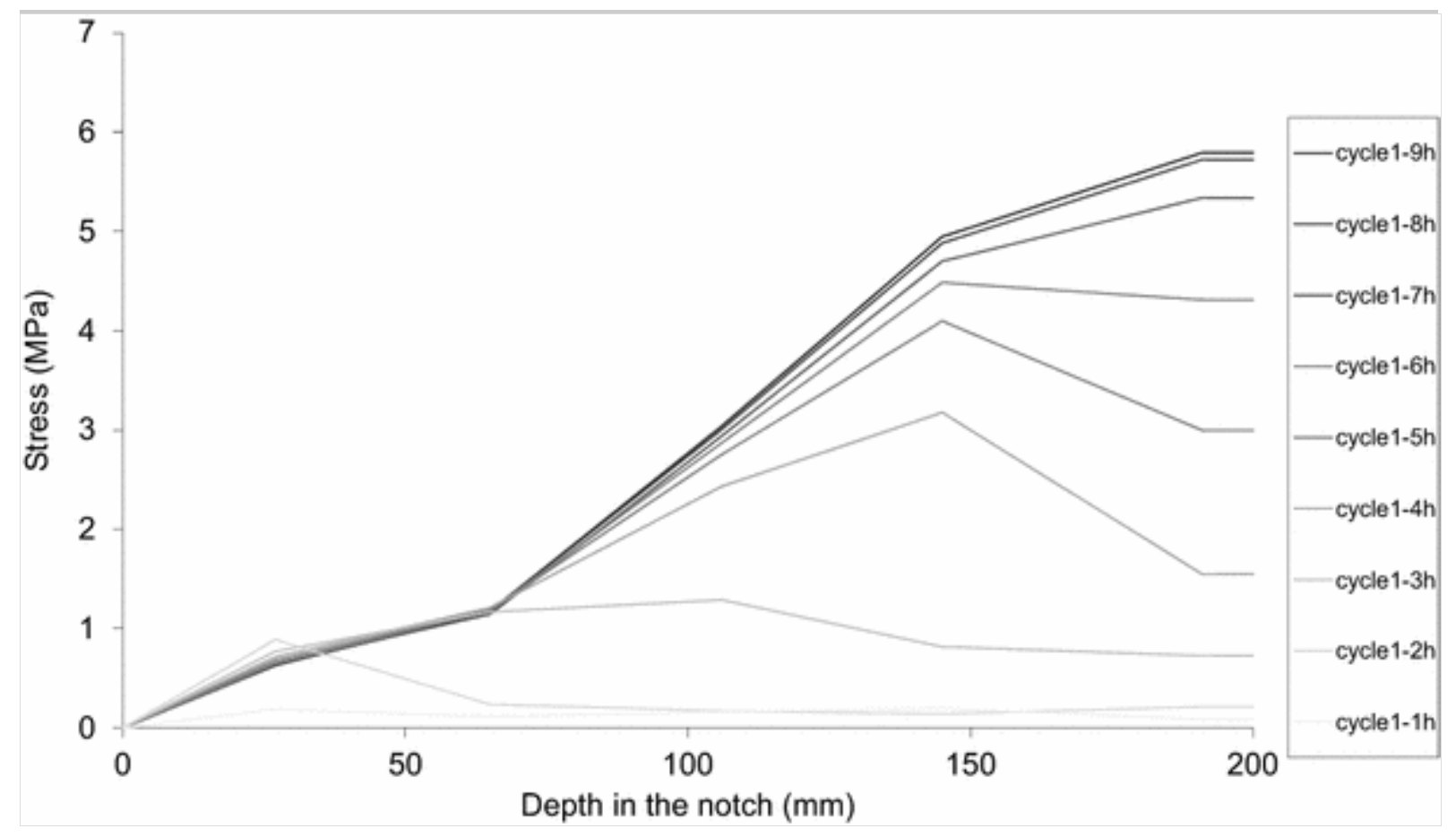

The results indicated that the stress along a notch filled with water and generated by the phase changes during a freeze-thaw cycle varies both in space and time as in the notched specimen cube of $\S 3.3$. The maximum stress increased with time and its location moved deeper into the notch (Fig. 10). The pressure profile variation in the notch provided interesting information on the mechanism of the development of stress due to freezing: the stress begins to grow at the top of the notch where freezing creates an ice plug and allows higher stress to be developed in deeper parts of the notch.

Stress evolution along a notch during a freeze- thaw cycle

Theoretical model predictions cannot be easily compared to our results because modeling does not account for a number of phenomena, such as fluid migrations in the porous matrix, which are yet poorly understood (\$2.2). For this reason, we decided to summarize the results obtained here for stress evolution with time and depth in the notch in order to build some empirical model. But it is difficult to directly associate the curves presented above (Fig. 10) to a mathematical formulation. However, the evolution of the stress generated by freezing may also be represented over time at the five different measurement depths (Fig. 11). 


\section{Fig. 11}

Stress evolution at five different measurement depths in the notch $(27,65,106$, $145,191 \mathrm{~mm}$ ) during the first freeze-thaw cycle

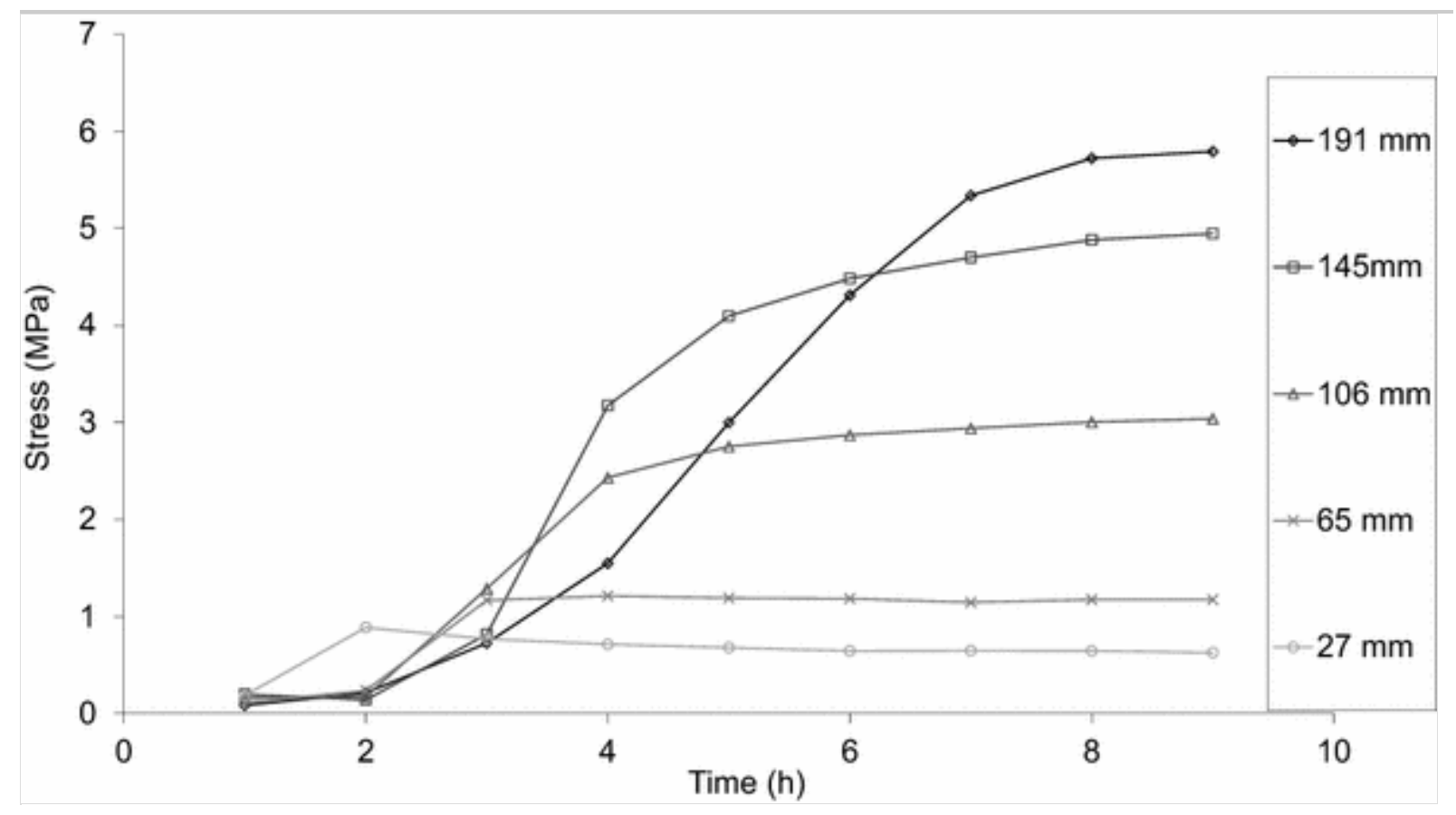

The mathematical formulation must represent the evolution of stress with depth in the notch $(x)$ and the duration of freezing $(t)$. After several trials, the following expression was found to provide an approximation for stress evolution:

$$
\sigma(x, t)=a\left[1-\exp ^{-b t}\right]\left[1-\exp ^{-c t^{3}}\right]
$$

where $a, b$ and $c$ are three coefficients depending on the spatial variable, the depth into the notch here. These coefficients, $a, b$ and $c$, can be determined at the five depths of measurement (Fig. 12).

\section{Fig. 12}

Evolution of the coefficients $a, b, c$ with the depth in the notch $x$

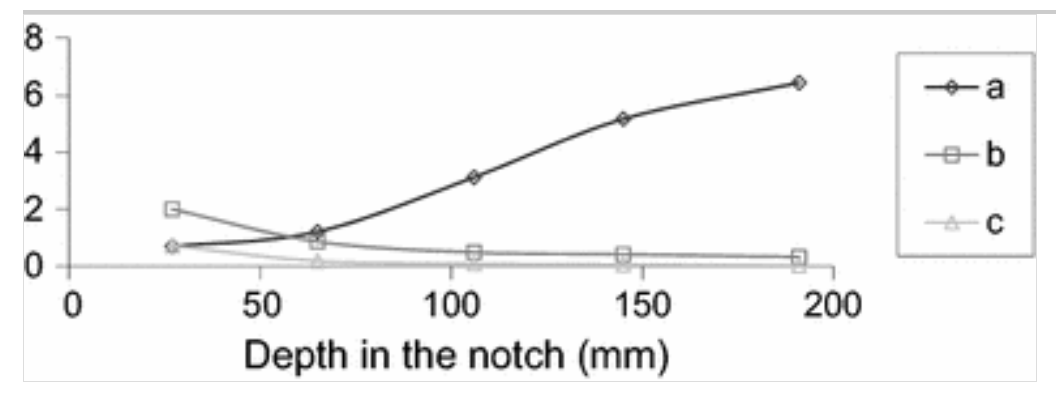


The evolution thus established for each of these coefficients is also described by the following functions:

$$
a(x)=a_{1}\left[1-\exp ^{-\frac{x^{2}}{a_{2}}}\right]=\sigma_{\text {risk }}(x)
$$

$b(x)=\frac{b_{1}}{x} \quad$ et $\quad c(x)=\frac{c_{1}}{x^{2}}$ (positive functions) with $x$ between 0 and $L$, the depth of the notch.

The coefficient $a$ corresponds to the envelope curve of the spatiotemporal evolution of the stress in the notch. Corresponding to the stress reached in each depth $x$ in an infinite time, this coefficient will now be called the maximum stress value along the notch.

\section{Parameterizing the stress generated by freezing in an open crack}

To be usable, this mathematical model needs to be expressed in terms of physical quantities. Past studies (Bost 2008) have highlighted the importance of the crack geometry and the pore network of rock on the effects due to freezing. For these reasons, the influences of the type of limestone and the geometry of the notch were studied with additional experiments.

\section{Influence of rock's pore network}

Principle and experimental setting

To study the influence of the pore network on the stress generated by freezing, the same experimental setting as that of $\S 3.2$ was applied to two other isotropic limestones. Table 4 presents the characteristics of pore networks for the three different limestones. The pore size distribution of the three limestones measured by mercury intrusion porosimetry is characterized by one main family (Fig. 13). However, each limestone presents a different porous network: Chamesson limestone has a high porosity and Pierre de Lens limestone has an important breakthrough radius (Table 4 ).

Fig. 13

Pore size distribution graphs for the three limestones 


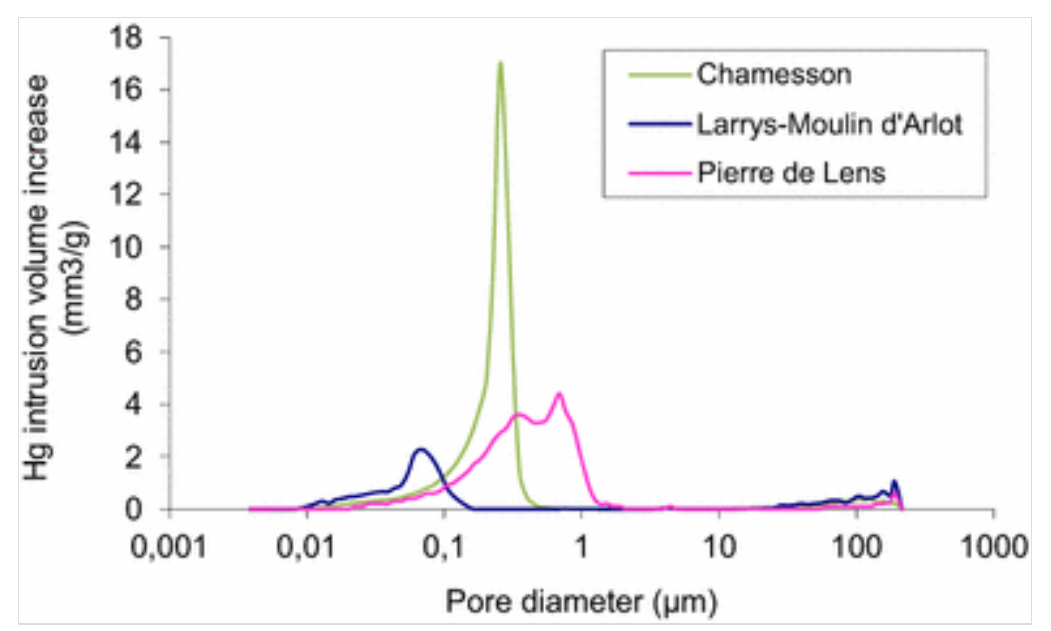

The maximum stress depends on porous network

The maximum stress during a cycle along the notch increases linearly with depth (Fig. 14). The value increases to a limit value for two of the studied limestones (Fig. 14: Chamesson and Pierre de Lens). This limit value is strongly related to the breakthrough radius (Fig. 15). As the permeability is proportional to the square of the breakthrough radius in case of one main pore family from the pore size distribution (Letavernier 1984), the more permeable a limestone is, the lower the maximum stress generated by freezing. Therefore, the porous network of rock seems to serve as an escape route during the spread of the freezing front in the notch for still liquid water contained in the bottom of the notch and pressurized by the development of an "ice plug".

Fig. 14

Profiles of maximum stress along the notch for three different limestones (Larrys, Pierre de Lens, Chamesson) 


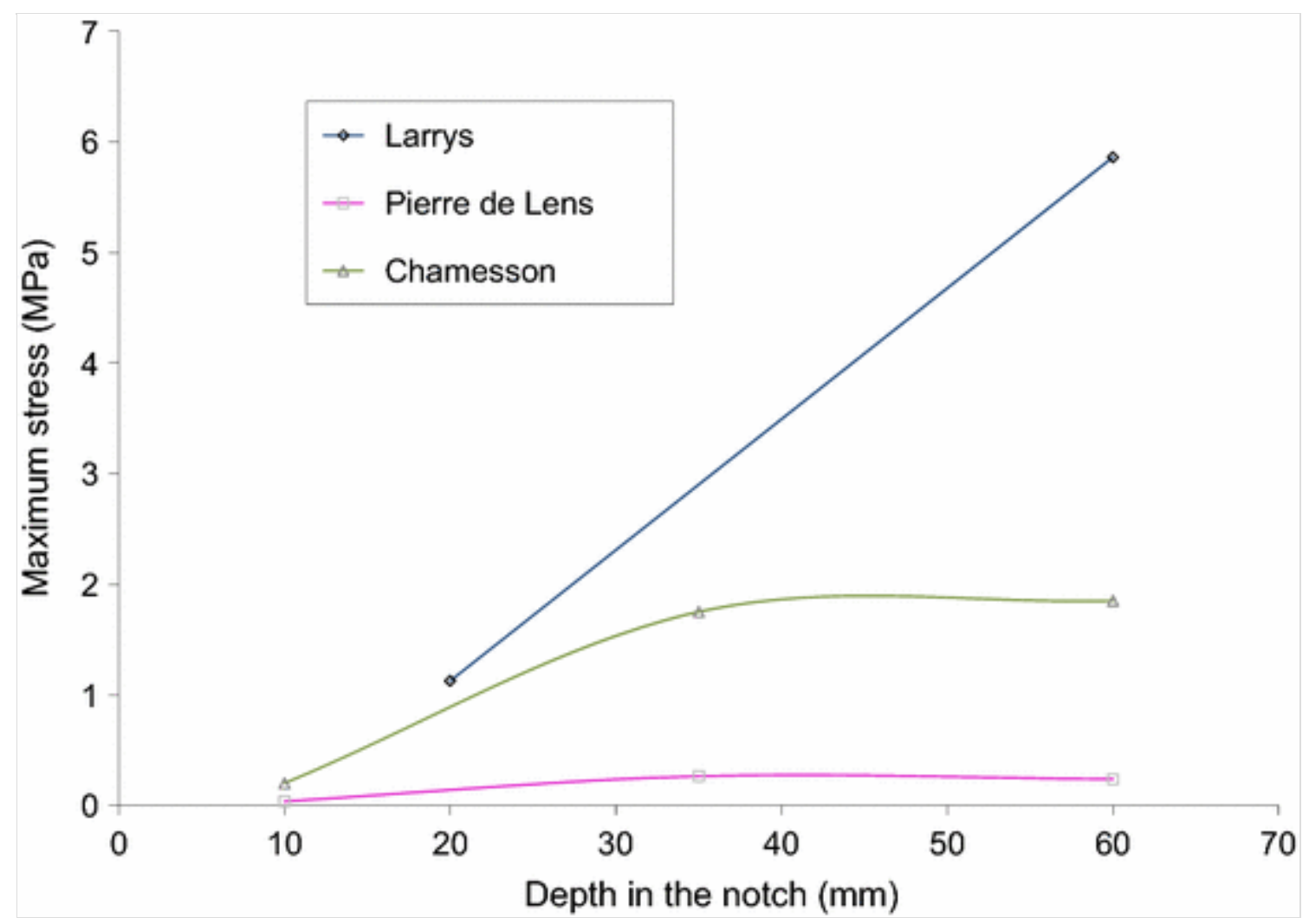

Fig. 15

Maximum stress at the bottom of the notch versus breakthrough radius for three different limestones (Larrys, Pierre de Lens, Chamesson)

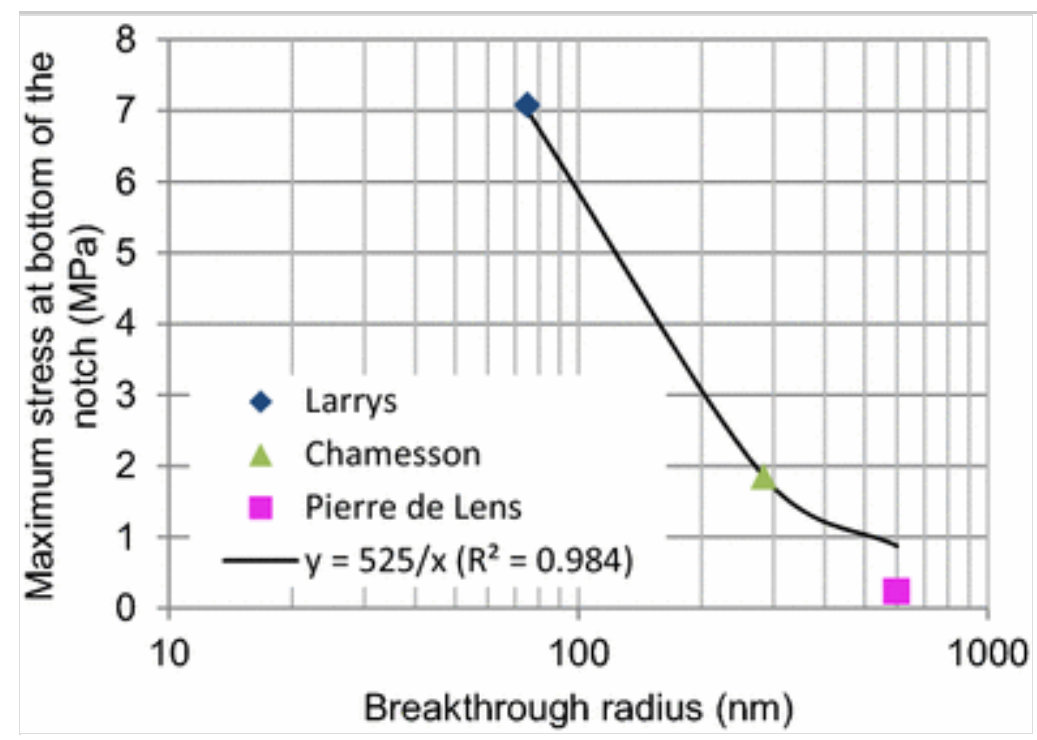

AQ6

\section{Influence of open crack geometry}

Principle and experimental setting

To assess the influence of the geometry of the notch, a new series of experiments was set up. The same experimental protocol as that of $\S 3$ with 
15-cm-side cubes (§3.2) was applied to four 4-cm cubes of our reference limestone, Larrys, notched at different depths and thicknesses. In each notch, in the same manner as above, pressure sensors were positioned. The obtained maximum stress was compared to the results already obtained with the over-cored hollow cylinder (§4.4.2) and the 15 -cm-side cubes $(\S 3.3)$.

\section{The maximum stress depends on geometry}

The linear approximation of the maximum stress during a cycle along the notch versus the product of thickness with depth of the notch carried on the notched 4-cm-side cubes is also valid for the linear part of the maximum stress curve in the cases of the $15-\mathrm{cm}$-side cubes and the over-cored hollow cylinder (Fig. 16). The product of thickness with depth of the notch actually corresponds to the amount of water located above the point considered in the notch.

\section{Fig. 16}

Profile of maximum stress at the depth $x$ in the notch versus the product of thickness $e$ with depth $x$ of the notch

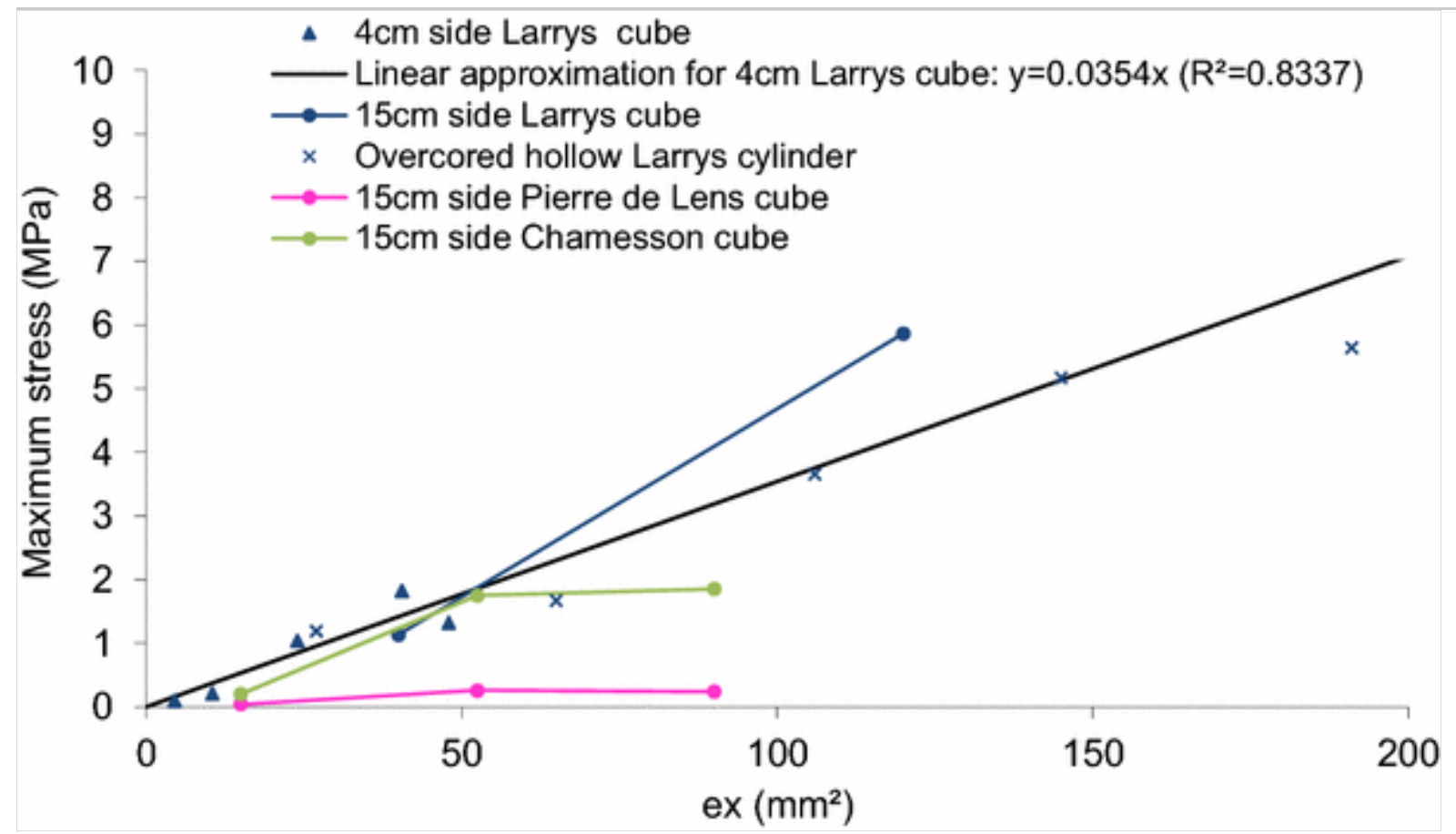

Whatever the type of limestone or sample, the maximum value of stress which occurs at a given depth in a cycle is proportional to the amount of water located above in the notch to a limit value. This limit value is determined by the breakthrough radius of the pore size distribution for the three studied limestones (§5.1.2). 


\section{Parameterized model of the stress generated by freezing}

Parameterizing the maximum stress

This dual observation of the influence of limestone's pore network and geometry of the notch on stress determined the maximum value attainable at a given depth during a freeze-thaw cycle: there is a critical depth value, $x_{c}$, beyond which the maximum stress remains constant. The maximum stress varies linearly with depth for depths less than $x_{c}$. These results can be put as follows:

$$
\begin{cases}\text { if } \quad x \leq x_{c}=\frac{\sigma_{\lim }}{\alpha e}, & \sigma_{\max }(x)=x e \alpha \\ \text { if } \quad x \geq x_{c}=\frac{\sigma_{\lim }}{\alpha e}, & \sigma_{\max }(x)=\sigma_{\lim }\end{cases}
$$

where $\sigma_{\lim }$ is the limit value of stress and $\alpha$ is a coefficient, constant regardless of the limestone or the geometry of the notch and equal to $0.0354 \mathrm{MPa} / \mathrm{mm}^{2}$ for our experimental studies (Fig. 16). In addition, $\sigma_{\text {lim }}$ can be estimated with good approximation from the breakthrough radius $R$ (Fig. 15). Therefore, according to our experimental results:

$$
\sigma_{\lim }=\frac{525}{R} .
$$

In this Eq. (9), $\sigma_{\text {lim }}$ is expressed in $\mathrm{MPa}$ and $R$ in $\mathrm{nm}$.

\section{Parameterized model of maximum stress value along the notch}

In evaluating the maximum stress at the bottom of the notch with Eq. (8) and noting also that, according to our various experimental results, the coefficient $a_{2}$ in Eq. (7) is always close enough to the square of the critical depth, $x_{c}$, the maximum stress along a deep $L$ and thick $e$ notch, is entirely determined by the following equation:

$$
\sigma_{\text {risk }}(x)=a_{1}\left[1-\exp ^{-\frac{x^{2}}{a_{2}}}\right] \quad \text { where } \quad a_{2}=x_{c}^{2}=\left(\frac{\sigma_{\text {lim }}}{\alpha e}\right)^{2},
$$

and 


$$
\left\{\begin{array}{l}
\text { if } \quad L<x_{c}, \quad a_{1}=\frac{\alpha e L}{1-\exp \left(-\left(\frac{\alpha e L}{\sigma_{\lim }}\right)^{2}\right)} \\
\text { if } \quad L>x_{c}, \quad a_{1}=\frac{\sigma_{\lim }}{1-\exp \left(-\left(\frac{\alpha e L}{\sigma_{\lim }}\right)^{2}\right)}
\end{array} .\right.
$$

This model summarizes all our experimental results with some consistency by comparing the evolution of the stress along the notch according to our measurements and this one determined by the model (Fig. 17). In an open limestone crack saturated with water, if the depth of the crack is lower than the critical depth, freezing-induced stress increases to a maximum value which depends on the location in the crack and is lower than the limit value. If the depth of the crack is higher than the critical depth, freezing-induced stress increases to the limit value. The limit value is related to the pore network of the limestone. The critical depth depends on this limit value and the thickness of the crack. The narrower a crack is, the lower the value of the critical depth is. Therefore, this empirical model developed with different limestones and different geometries of a single crack can be applied to evaluate freezinginduced stress in simple crack networks of limestone rock masses. Moreover, we can underline that, as for our experiments, freeze-thaw cycles were performed without a gradual cooling rate and high water saturation level, conditions were severe enough that the value also estimated for stress is conservative.

\section{Fig. 17}

Experimental and theoretical maximum stresses along the notch for a cube specimen and cylinder specimen 


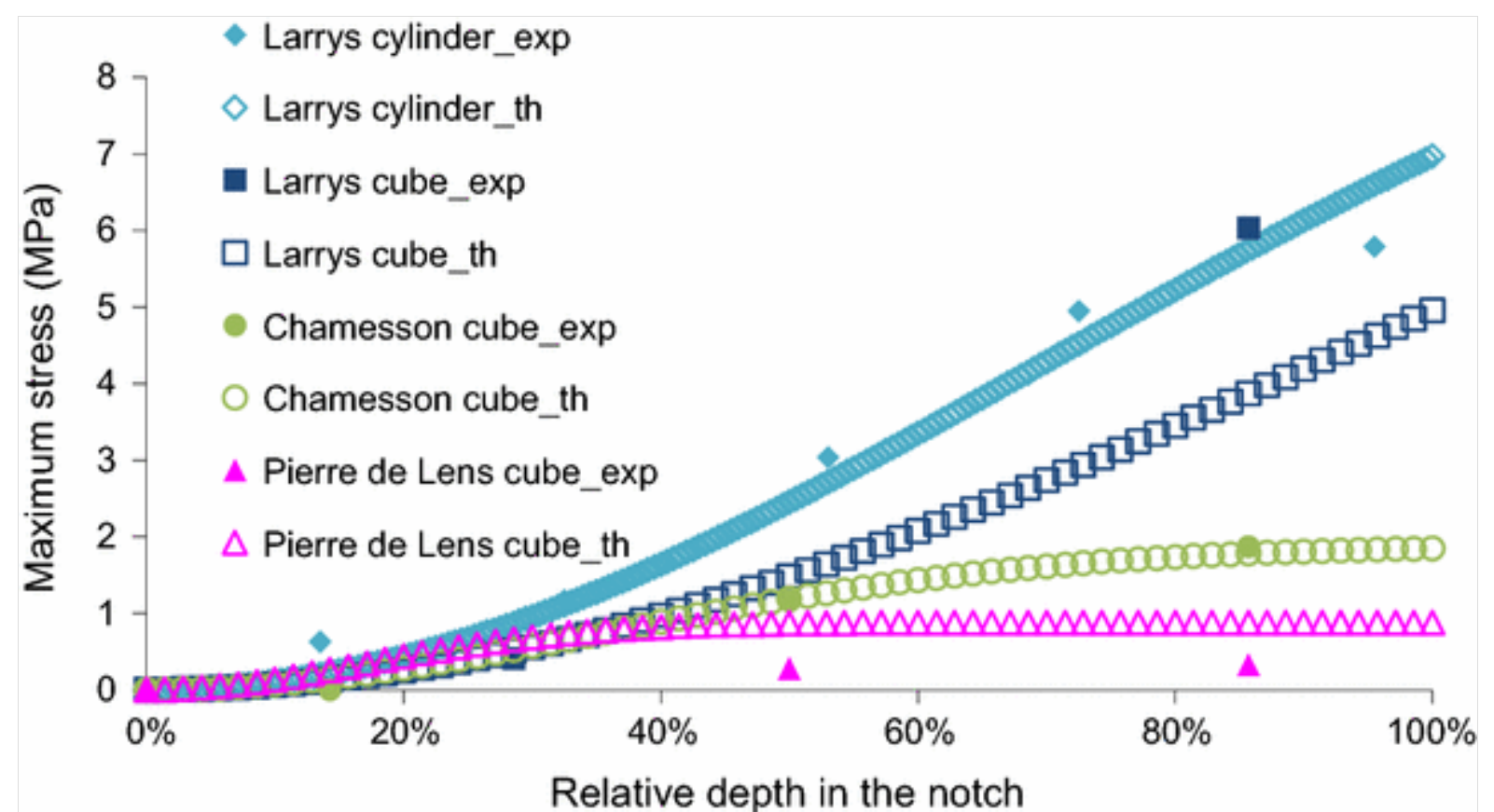

AQ7

Application to a real case in the French subalpine ranges

We give in this section an application example of the above results to estimate the stress generated by freezing in a real crack. We took the example of the cliffs of the Gorges de la Bourne in the French subalpine ranges including vertical cracks and subject to recurrent rockfalls. Frayssines and Hantz (2009) studied specifically the rockfall named Ranc that occurred in January 2004. The unstable mass was a 2.5-m thick (average) overhang block made of Urgonian limestone. It created a scar from a maximum height of $20 \mathrm{~m}$ by $50 \mathrm{~m}$ wide which indicates alteration and traces of water circulation (Frayssines 2005), suggesting the initial subvertical crack to be approximately $1 \mathrm{~cm}$ thick by $16.5 \mathrm{~m}$ deep with $3.5 \mathrm{~m}$ of rock bridges at the bottom of the crack. 
Mercury intrusion porosimetry measurement showed a breakthrough radius of $60 \mathrm{~nm}$ for the Urgonian limestone. The formulas (9) and (8), respectively, estimated the limit value of stress as $8.75 \mathrm{MPa}$ and, so, the critical depth $x_{\mathrm{c}}$ as $0.025 \mathrm{~m}$. This value for stress seems to be a more reasonable value compared to the predictions of the simplified models mentioned in "Existing models of the stress generated by freezing in a crack". According to Eq. (10) and assuming the water height in the crack is superior to $x_{\mathfrak{c}}, 10 \mathrm{~m}$ (2/3 filling), for example, the profile of the stress along the notch would be further given by:

$$
\sigma_{\text {risk }}(x)=8.75\left[1-\exp ^{-\frac{x^{2}}{0.611 .10^{-3}}}\right]
$$

with $x$, depth under water level, in $\mathrm{m}$ and $\sigma_{\text {risk }}$ in $\mathrm{MPa}$.

The analysis of crack propagation under this stress requires the estimation of the stress intensity factor at the crack tip. However, if we compare the stress calculated at the bottom of the notch to the tensile strength measured at the rock bridges (Frayssines and Hantz 2009), 3.2 MPa, we see that there is actually a possibility of failure by freezing. Therefore, the developed empirical model provides a more realistic value for freezing-induced stress which is suitable for explaining observed weathering. This example justifies the utility and relevance of such results for the stability analysis of rock masses.

\section{Conclusions}

The phenomenon of propagation of crack networks existing in rock masses during freezing is qualitatively well-known. However, few quantitative data exist on this subject and no proper model can be used to evaluate the stress at the origin of this propagation. The various experiments implemented in this study were used to provide an explanation of the mechanism of freezing in an open crack and some quantitative data to fill existing gaps. Stress induced by freezing in an open crack develops due to the spread of an ice plug formed at the top of the crack. Pressure is thus created in the still liquid water at the bottom of the crack. This stress is limited by the possible flow of water through the surrounding pore network of limestone.

We were able to establish an empirical model of the profile of the stress generated by freezing along a notch in the conditions of the experiments we conducted. This empirical model yields a more realistic evaluation of 
freezing-induced stress in an open crack. Importantly, the result of our research demonstrates that the envelope curve of this model can be completely defined by the knowledge of the pore network of rock (breakthrough radius) and the geometry of the notch filled with water.

However, this model was developed for limestone and for one single open crack. This model needs to be tested on other rocks and be validated by in situ stress measurements. Moreover, regarding the rock masses, the tortuosity of the cracks and the overall permeability of their network should be considered.

In conclusion, if this result is confirmed and supplemented by further studies on other rocks and subject to validation by in situ stress measurements, it will significantly contribute to the estimation of stress due to freezing in rock masses and analysis of the risks associated with their instability.

\section{Acknowledgments}

The authors thank the group at the rock mechanics laboratory of IFSTTAR for its support in performing the numerous experiments of this study. We also thank the two anonymous reviewers whose suggestions have greatly improved the manuscript.

\section{References}

AFNOR (1973) NF B10-504. French Standard: Quarry products

- Limestones-Measurement of the coefficient of water absorption AQ8

Akyurt M, Zaki G, Habeebullah B (2002) Freezing phenomena in ice-water systems. Energy Convers Manag 43:1773-1789.

doi:10.1016/S0196-8904(01)00129-7

Amitrano D, Arattano M, Chiarle M, Mortara G, Occhiena C, Pirulli M, Scavia C (2010) Microseismic activity analysis for the study of the rupture mechanisms in unstable rock masses. Nat Hazards Earth Sci 10:831-841

Amitrano D, Gruber S, Girard L (2012) Evidence of frost-cracking inferred from acoustic emissions in a high-alpine rock-wall. Earth Planet Sci Lett 341-344:86-93. doi:10.1016/j.eps1.2012.06.014

Berthier R (1958) La physique du gel. Bull RILEM 40:7-21 
Bost M (2008) Altération par le gel des massifs rocheux: Etude expérimentale et modélisation des mécanismes de génération des contraintes dans les fissures. Dissertation, Ecole Nationale des Ponts et Chaussées

Bourgeois E, Mestat Ph, Pucheu M (2012) CESAR-LCPC Abridged theoretical manual. Ifsttar-Itech. http://www.itech-soft.com/cesar/download /en/CESAR-MU\%28AbTh\%29-v2.0-GB.pdf AQ9

Bousquié P (1979) Texture et porosité de roches calcaires. Relations avec la perméabilité, L'ascension capillaire, la gélivité, la conductivité thermique. Dissertation, University of Pierre et Marie Curie, Paris VI

Bridgman PW (1912) Water, in the liquid and five solid forms, under pressure. Proc Am Acad Arts Sci 47:441-558

Chen TC, Mori N, Suzuki T, Shoji H, Goto T (2000) Experimental study on crack development pf rock specimens by freezing and thawing cycles. Soils Found 40(2):41-48

Clark M, Small J (1982) Slopes and weathering. Cambridge topics in geography, vol 2. Cambridge University Press, Cambridge

Davies MCR, Hamza O, Harris C (2001) The effect of rise in mean annual temperatures on the stability of rock slopes containing ice-filled discontinuities. Permafr Periglac Process 12:137-144. doi:10.1002/ppp.378

De Kock T, Boone MA, De Schryver T, Van Stappen J, Derluyn H, Masschaele B, De Schutter G, Cnudde V (2015) A pore-scale study of fracture dynamics in rock using X-ray micro-CT under ambient freeze-thaw cycling. Environ Sci Technol 49(5):2867-2874. doi:10.1021/es505738d

Derruau M (1996) Les formes du relief terrestre. Notion de géomorphologie, 8th edn. Armand Colin Publisher, Paris

Djaballah Masmoudi N (1998) Modélisation et expérimentation de la perméabilité et des mécanismes de transfert dans les milieux poreux au cours du gel. Dissertation, University of Pierre et Marie Curie, Paris VI 
Draebing D, Krautblatter M, Dikau R (2014) Interaction of thermal and mechanical processes in steep permafrost rock walls: a conceptual approach. Geomorphology. doi:10.1016/j.geomorph.2014.08.009

Eshelby JD (1957) The determination of the elastic field of an ellipsoidal inclusion and related problems. Proc R Soc Lond A 241:376-396. doi:10.1098/rspa.1957.0133

Everett DH (1961) Thermodynamics of frost damage to porous solids. Trans Faraday Soc 57:1541-1551. doi:10.1039/TF9615701541

Fahey BD, Lefebure TH (1988) The freeze-thaw weathering regime at a section of the Niagara escarpment on the Bruce Peninsula, Southern Ontario, Canada. Earth Surf Process Landf 13:293-304. doi:10.1002/esp.3290130403

Frayssines M (2005) Contribution à l'évaluation de l'aléa éboulement rocheux (rupture). Dissertation, University of Joseph Fourier, Grenoble

Frayssines M, Hantz D (2006) Failure mechanisms and triggering factors in calcareous cliffs of the Subalpine Ranges (French Alps). Eng Geol 86:256-270. doi:10.1016/j.enggeo.2006.05.009

Frayssines M, Hantz D (2009) Modelling and back analysing failures in steep limestone cliffs. Int J Rock Mech Min Sci 46:1115-1123. doi:10.1016/j.ijrmms.2009.06.003

Freire-Lista DM, Fort R, Varas-Muriel ML (2015) Freeze-thaw fracturing in building granites. Cold Reg Sci Technol 113:40-51.

doi:10.1016/j.coldregions.2015.01.008

Groupe Falaise (2001) Prévention des mouvements de versants et des instabilités de falaises. Confrontation des méthodes d'étude des éboulements rocheux dans l'arc alpin. Programme Interreg IIC-Falaises Méditerranée Occidentale et Alpes Latines

Hall K (1986) The utilization of the stress intensity factor (KIC) in a model for rock fracture during freezing: an example from Signy Island, the maritime Antarctic. Br Antarct Surv Bull 72:53-60 (http://web.archive.org/web/20150708051850/http: 


\section{//www.antarctica.ac.uk/documents/bas_bulletins/bulletin72_06.pdf)}

Hirschwald J (1912) Handbuch der bautechnischen gesteinsprüfung. Borntraeger, Berlin

Huygens C (1666) Effet du froid sur l'eau renfermée dans un canon de pistolet. Volume de l'Académie Royale des sciences de Paris

Ishikawa M, Kurashige Y, Hirakawa K (2004) Analysis of crack movements observed in an alpine bedrock cliff. Earth Surf Process Landf 28:883-891. doi:10.1002/esp.1076

Iskandar A (1990) Caractérisation de l'espace poreux de roches sédimentaires par l'étude d'équilibres capillaires. Dissertation, Ecole Nationale des Ponts et Chaussée, Paris

Javey C (1972) Bull BRGM III(1):40-66

AQ10

Krautblatter M, Funk D, Gunzel FK (2013) Why permafrost rocks become unstable: a rock-ice-mechanical model in time and space. Earth surf Process Landf 38:876-887. doi:10.1002/esp.3374

Letavernier G (1984) La gélivité des roches calcaires. Relations avec la morphologie du milieu poreux. Dissertation, University of Caen

Lévy C, Baillet L, Jongmans D, Mourot P, Hantz D (2010) Dynamic response of the Chamousset rock column (Western Alps, France). J Geophys Res. doi:10.1029/2009JF001606

Litvan GG (1978) Freeze-thaw durability of porous building materials. Durability of building materials and Components. ASTM Spec Tech Publ 691:455-463

Lliboutry L (1964) Traité de glaciologie: Glaciers, variations du climat, sols gelés, vol 2. Masson \& cie Publishers, Paris

Mateos RM, Garcia-Moreno I, Azanon JM (2012) Freeze-thaw cycles and rainfall as triggering factors of mass movements in a warm Mediterranean region : the case of the Tramuntana range (Majorca, Spain). Landlsides 
Matsuoka N (2001) Direct observation of frost wedging in alpine bedrock. Earth Surf Process Landf 26:601-614

Matsuoka N (2008) Frost weathering and rockwall erosion in the southeastern Swiss Alps: Long-term (1994-2006) observations. Geomorphology 99:353-368. doi:10.1016/j.geomorph.2007.11.013

Matsuoka N, Murton J (2008) Frost weathering : recent advances and future directions. Permafr Periglac Process 19:195-210. doi:10.1002/ppp.620

Murton JB, Peterson R, Ozouf JC (2006) Bedrock fracture by ice segregation in cold regions. Science 314:1127-1129.

doi:10.1126/science. 1132127

AQ11

Panet M (1976) La mécanique des roches appliquée aux ouvrages de génie civil. Ecole Nationale des Ponts et Chaussées Edition

Pellerin FM (1980) La porosimétrie au mercure appliquée à l'étude géotechnique des sols et des roches. Bull Liaison Labo P Et Ch 106

PIARC G2 (1999) Technical Committee 7.2 Natural Disaster Reduction.

Natural Disaster Reduction for Roads-Final Report. ISBN 2-84060-109-5

Pouya A (1991) Comportement rhéologique du sel gemme. Application à l'étude des excavations souterraines. Dissertation, Ecole Nationale des Ponts et Chaussées

Powers TC (1949) The air requirement of frost-resistant concrete. Proc Highw Res Board 29:184-211

Powers TC, Helmuth RA (1953) Theory of volume changes in hardened Portland cement paste during freezing. Proc Highw Res Board 32:285-297

Prick A (1995) Dilatometrical behaviour of porous calcareous rock samples subjected to freeze-thaw cycles. Catena 25:7-20 
Salençon, J (2002) Mécanique des Milieux Continus, Editions de l'Ecole Polytechnique, France

Scherer GW (1999) Crystallization in pores. Cem Concr Res 29:1347-1358

Teixeira J (2001) L'étrange comportement de l'eau ultra-froide. Pour la Sci 28:84-91

Tharp TM (1987) Conditions for crack propagation by frost wedging. Geol Soc Am Bull 99:94-102

Valadas B (1975) Quelques résultats d'observations de terrain en matière de gélifraction actuelle dans le Massif Central français. VIth International Congress Les problèmes posés par la gélifraction. Recherches fondamentales et appliquées, rapport no 109, Fondation Française d'Etudes Nordiques: Le Havre

Walder J, Halet B (1985) A theoretical model of the fracture of rock during freezing. Geol Soc Am Bull 96:336-346

Wegmann M, Gudmundsson GH (1999) Thermally induced temporal strain variations in rock walls observed at subzero temperatures. In: Hutter K, Wang Y, Beer H (eds) Advances in cold region thermal engineering and sciences. Lecture Notes in Physics. Springer, Heidelberg, pp 511-518 